Ego identity, self-esteem, and academic achievement among EFL learners: A relationship study

Mohammadi, Hedieh

Imam Reza International University, Iran (Hediyemohamadi.eng@gmail.com)

Akbari, Omid $\$

Imam Reza International University, Iran (omidakbari@imamreza.ac.ir)

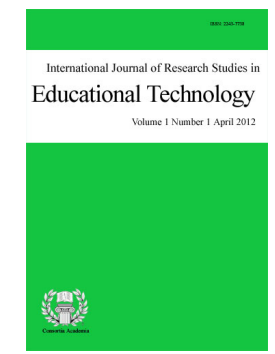

ISSN: $2243-7738$ Online ISSN: 2243-7746

OPEN ACCESS

\title{
Abstract
}

This study particularly aimed at investigating the relationships of ego identity, self-esteem and academic achievement among EFL university students. Ego identity is the core element through psychological issues and it sets social and cognitive structure of individuality. Self-esteem is a need for humans and it is effectual to achieve the wanted task. Four universities were randomly sampled. Participants were 217 students of whom 158 were females and 59 were males. The students responded to scale of the EOM-EIS and Rosenberg Self-Esteem Scale. SPSS was run using Cronbach's alpha and Pearson correlation coefficient were applied. The results revealed all four subscales of ego identity except for identity-foreclosure, had a significant relationship with self-esteem, and also all subscales of ego identity had significant relationship with academic achievement. And also, there was significant relationship between self-esteem and academic achievement. Consequently, ego identity and self-esteem are influential in academic achievement of the students. The current study revealed that identity achievement plays an important role in the locus of identity formation. Therefore, learners with high self-esteem revealed a sign of progress in their academic achievement.

Keywords: ego identity; self-esteem; academic achievement; EFL learners; correlation 


\section{Ego identity, self-esteem, and academic achievement among EFL learners: A relationship study}

\section{Introduction}

According to Kroger (2000), adolescence is a developmental period during which young begin to examine their beliefs, identify their strengths and limitations and establish their competencies, during a developmental phase of identity formation. Erikson is credited for his influential work discussing the concept of identity formation, following Frued's (1970) postulation of the psychosexual stages from infancy to early adolescence; Erikson believed that ego development extended beyond childhood. Josselson (1982) further asserted that identity formation continues across the life span, with the major crisis of identity occurring during adolescence. Hartmann (1980) described that identity formation process, however, occurs when an individual begins to establish a sense of self as an independent intrapsychic structure without overly relying on identifications. Kroger (2000) described that earlier identifications are not lost; rather they are incorporated into the identity formation process. Ideology refers to a value orientation or set of beliefs which provide a framework for organizing one's experience. Moshman (2005) believed that accompany with vocational direction, are the areas around which choices are made. Erikson postulates that issues of identity come to ascendency during adolescence, and according to the epigenetic principle, it will be revised and renewed in later stages of life cycle.

It is announced that "self-esteem was generally considered to serve as a need which is the most basic type of motivation" (Pajares, 2003, p. 140). Self-esteem can be considered as the need to maintain the self-sameness or identity. Coopersmith (1981) pointed out in this sense; it acts as a protector of the self against threats from the environment and protects the integrity of the self during stressful situation. Lane (2004) believed that self-esteem keeps the behavior of the individual at a certain level that maintains social functioning. High self-esteem makes people more willing to speak up in groups and to criticize the group's approach. Branden (1991) described that leadership does not stem directly from self-esteem, but self-esteem may have indirect effects. Coopersmith (1981) pointed out that relative to people with low self-esteem, those with high self-esteem show stronger in-group favoritism, which may increase prejudice and discrimination.

\subsection{Purpose of the study}

The purpose of the present study wants to investigate:

$>\quad$ Is there any significant relationship between ego identity and self-esteem of EFL learners?

$>\quad$ Is there any significant relationship between ego identity and academic achievement of EFL learners?

\section{Methodology}

\subsection{Participants}

The participants of the present study comprised 217 university students who have B.A and M.A. in English literature, English language teaching and English translation at Imam Reza, Khayam, Tabaran, and Islamic Azad Universities, Iran in November 2015. Out of 217 participants, 158 students were female and 59 students were male. Their age ranged between 18 and 39 with different language proficiency in the academic year of 2015-2016. The participant will be sampled randomly through the present research. The participants were fresher, sophomore, junior and senior and the rest of the participants were graduated. All of the subjects in the current study were volunteers and it was prevented to force students to take part, in addition the purpose of the study was told for those who were volunteers. 


\subsection{Instruments}

Two instruments are employed in the process of data collection for the present study the related instruments used, are as follows: Identity Achievement status scale of the EOM-EIS (Bennion \& Adams, 1986) and Rosenberg Self-Esteem Scale (Rosenberg, 1965).

Identity Achievement Scale of EOM-EIS - Identity measure used in this study, the EOM-EIS, stands for Extended Objective Measure of Ego Identity Status. Last version of this questionnaire was developed by Adams and Bennion. It contains 64 items which measures four areas of identity crisis subsets based on Marcia (1980), are as following:

$>$ Identity-Achievement: individuals have considered occupational choices through a crisis period.

> Identity-Moratorium: individuals are attempting some compromise among parental wishes, society's demand, and their own capabilities and they are still in crisis period and unable to make a commitment.

Identity-Foreclosure: individuals have made a commitment without experiencing a crisis and they are becoming what others have intended for them.

$>$ Identity- Diffusion: individuals lack commitment; they may or may not have experienced a crisis period, they have not decided upon an occupation nor they have not concerned about it. All items were answered using a 5-point Likert-type scale format ranging from strongly disagree to strongly agree. The reliability and validity of the ego identity status questionnaire had been proven in various studies. Adams et al. following various studies had been reported satisfactory validity and reliability coefficients respectively and the reported reliability coefficient in the present study using Cronbach's alpha as .83 for identity diffusion, 0.77 for identity foreclosure, .74 for identity moratorium, and .81 for achievement identity in the present study.

Rosenberg Self-Esteem Scale - Self-esteem scale developed by Rosenberg (1965), it was used to measure global self-esteem of the individuals by measuring both positive and negative feelings about the self. Rosenberg self-esteem contains 10 items. All items were answered using a 4-point Likert-type scale format ranging from strongly agree to strongly disagree. In addition, it was reported satisfactory validity and reliability coefficients. The reported reliability alpha for the measure of global self-esteem in the present study was .79 in the present study. The scale is believed to be uni-dimensional.

\subsection{Data Collection Procedure}

Data collection procedure started in November 2015 and the sample of participants with different degree and various proficiency levels are identified in four universities of Mashhad as Khayam, Tabaran, Imam Reza and Azad University. As the researcher determined to select 217 students randomly, it was impossible to distribute questionnaire at the same time and at one place, so this process was done through different sessions in different universities. In addition, the permission of professors for taking time to distribute questionnaires was mandatory. At first the identity achievement questionnaire was given to students to fill it at home and it was given to student the scale named Rosenberg Self-Esteem (general self-esteem). It consisted of 10 items a long with a 4-point Likert-type scale. As the numbers of the items are limited in 10 items, the students were asked to answer it at a given time. So the current data was given to the students in order to complete it appropriately at the exact given time. The self-Esteem questionnaire was given to learners 20 minutes before the class stated in order not to disturb the class. A straightforward instruction regarding what the respondents should do and brief information about the purpose of the questionnaire and its scope was provided in their native language (i.e. Persian). They were also given an opportunity to ask questions and to offer suggestions. 
Mohammadi, H., \& Akbari, O.

\subsection{Data Analysis Procedure}

The obtained score were transformed into SPSS. For examining the reliability indices of three scales, Cronbach's alpha was utilized. To provide detailed information that describes the survey responses, the descriptive statistics for all scales are presented. To determine the relationship among variables under study and age, Pearson correlation coefficient was employed.

\section{Results}

This study examined the relationship between self-esteem, ego identity and academic achievement among EFL learners. This research is bound to realize the effect of two individual variables and ego identity's subscales on the part of learners and academic achievement of them. This part provides detailed results of the data analyses. First, the descriptive statistics for all scales used in the study are presented. Descriptive statistics provide detailed information that describes the survey responses. Then, each research question is outlined according to the data analysis procedure and the results of the analyses. Tables provide detailed descriptions of the findings.

\subsection{Descriptive Statistics}

Number of participants, minimum and maximum scores, means and standard deviations of each of the scales used in the study are presented in Table 1 and Table 2. Table 1 displays descriptive statistics of the comprising factors of EFL students' ego identity, in other words, identity-achievement, identity-moratorium, identity-foreclosure and identity-diffusion, while, Table 2 indicates descriptive statistics of EFL learners' self-esteem.

\section{Table 1}

Descriptive Statistics of EFL Learners' identity achievement

\begin{tabular}{lccccc}
\hline & $\mathrm{N}$ & Minimum & Maximum & Mean & SD \\
\hline IA & 217 & 24.00 & 73.00 & 54.49 & 7.78 \\
IM & 217 & 20.00 & 70.00 & 48.33 & 5.62 \\
IF & 217 & 16.00 & 42.00 & 21.05 & 4.41 \\
ID & 217 & 17.00 & 42.00 & 20.12 & 3.13 \\
Valid N (listwise) & 217 & & & & \\
\hline
\end{tabular}

Note. $\mathrm{IA}=$ Identity-Achievement, IM = Identity-Moratorium, IF = Identity-Foreclosure, ID = Identity-Diffusion

The possible range of score for each subscale of learners' ego identity is between 16 and 80 . As it can be seen in table 3.1, the lowest minimum score of the subscales of learners' ego identity is related to Identity-Foreclosure (16.00) and highest minimum is related to Identity-Achievement (24.00). Besides, the lowest maximum is related to Identity-Foreclosure and Identity-Diffusion (42) and highest maximum is related to Identity-Achievement (73.00). Moreover, among four subscales of learners' ego identity, the highest mean score is related to Identity-Achievement (54.49) and the lowest mean score is related to Identity-Diffusion (20.12).

As the table 2 shows, number of participants in the present study is 217 . The possible range of score for learners' Self-Esteem is between 10 and 40. As it can be seen in the table, the minimum score of learners' Self-Esteem is 14 and the maximum score is 38.00. Moreover, the mean score of the scale is 27.94. This mean score indicates that most of students have an average self-esteem. In addition, the standard deviation of this scale is 7.59 . 
Ego identity, self-esteem, and academic achievement among EFL learners: A relationship study

Table 2

Descriptive Statistics of EFL Learners' Self-Esteem

\begin{tabular}{lccccc}
\hline & N & Minimum & Maximum & Mean & SD \\
\hline SE & 217 & 14.00 & 38.00 & 27.94 & 7.59 \\
Valid N (listwise) & 217 & & & & \\
\hline
\end{tabular}

Note. $\mathrm{SE}=$ Self-Esteem.

\subsection{Research Questions and Findings}

To assess Research Questions 1 and 2 Pearson's Correlation Coefficient was conducted.

$>\quad$ Q1: Is there any significant relationship between ego identity and self-esteem of EFL learners?

$>$ H01: There is not any significant relationship between ego identity and self-esteem of EFL learners.

$>\quad$ Q2: Is there any significant relationship between ego identity and academic achievement of EFL learners?

$>$ H02: There is not any significant relationship between ego identity and academic achievement of EFL learners.

To answer question 1, which seeks to explore the possible association between ego identity and self-esteem, SPSS was run. Table 3 indicated the results of correlation coefficient.

Table 3

Correlations between ego identity and self-esteem of EFL learners

\begin{tabular}{llllll}
\hline & $1 . \mathrm{IA}$ & $2 . \mathrm{IM}$ & $3 . \mathrm{IF}$ & $4 . \mathrm{ID}$ & $5 . \mathrm{SE}$ \\
\hline 1.IA & 1 & & & & \\
$2 . \mathrm{IM}$ & .21 & 1 & & & \\
$3 . \mathrm{IF}$ & .17 & .23 & 1 & & \\
$4 . \mathrm{ID}$ & .11 & .21 & .14 & 1 & \\
$5 . \mathrm{SE}$ & $.63^{* *}$ & $.45^{* *}$ & .12 & $-.43^{* *}$ & 1 \\
\hline
\end{tabular}

Note. **Correlation is significant at the level of 0.01 .

As it can be seen in table 3, all four subscales of ego identity (Identity-Achievement, Identity-Moratorium, Identity-Foreclosure, and Identity-Diffusion) except for identity-foreclosure, have a significant relationship with self-esteem. So, the null hypothesis is rejected. As the table shows the highest correlation is related to Identity-Achievement and self-esteem $(r=.63, p=.000)$ and the lowest correlation is related to identity-foreclosure and self-esteem $(r=.12, p=.351)$. The only negative correlation is found between identity-diffusion and self-esteem $(r=-.43, p=.000)$.

Table 4

Correlations between ego identity and academic achievement of EFL learners

\begin{tabular}{llllll}
\hline & $1 . \mathrm{IA}$ & $2 . \mathrm{IM}$ & $3 . \mathrm{IF}$ & $4 . \mathrm{ID}$ & 5.ACH \\
\hline 1.IA & 1 & & & & \\
2.IM & .21 & 1 & & \\
3.IF & .17 & .23 & 1 & & \\
$4 . \mathrm{ID}$ & .11 & .21 & .14 & 1 & \\
$5 . \mathrm{ACH}$ & $.51^{* *}$ & $.39^{* *}$ & $-.21^{*}$ & $-.43^{*}$ & 1 \\
\hline
\end{tabular}

Note. **Correlation is significant at the level of 0.01 . $*$ Correlation is significant at the level of 0.05 . 
To answer question 2, which seeks to explore the possible association between ego identity and academic achievement, SPSS was run. Table 3 indicated the results of correlation coefficient. Table 4 , shows the results of correlation coefficient among four subscales of ego identity and academic achievement.

As table 4 indicates, all of the subscales of ego identity (Identity-Achievement, Identity-Moratorium, Identity-Foreclosure, and Identity-Diffusion) show significant relationship with academic achievement. Among these four subscales of ego identity Identity-Achievement indicates the highest relationship ( $r=.51, p=.009)$ and Identity-Foreclosure shows the lowest relationship $(r=.27, p=.035)$ with academic achievement. Hence, the null hypothesis is rejected.

\section{Discussions and conclusions}

Considering the first research question which asked whether ego identity (as measured by EOM- EIS) and self-esteem (as measured by Rosenberg Self-Esteem) influence on EFL learner's academic achievement or not, the present study revealed that there are significant relationships between all subscales of go identity (identity achievement, identity diffusion, and identity moratorium) except for foreclosure with self-esteem. The highest correlation is related to identity-achievement and self-esteem and the lowest correlation is related to identity-foreclosure and self-esteem. The only negative correlation is found between identity-diffusion and self-esteem.

Agolla (2009) claimed that identity achievement is central to academic achievement of students. The important point is that these subjects usually have high self-esteem and they can easily succeed in their course of their studies. These subjects have tendency to being independent through facing with burdensome processes. They have strong commitment to highly-developed set of beliefs and values. Erikson (1980), believed that the subjects have tendency to explore high exploration. They are able to sort out who they want to be and what their life's purpose is. They realize where their priorities are. They also think positive through what they choose; such as the right values and beliefs. At the other point, Adams (1989) has stressed the paramount importance of identity achievement in selecting occupational choices and ideologies in the other words an identity achievement subject has experienced a crisis period and is committed to an occupation and ideology. The subject has seriously considered several occupational choices and has made a decision on his own terms, even though his ultimate choice may be a variation of parental wishes. With respect to ideology, he seems to have reevaluated past beliefs and achieved a resolution that leaves him free to act. Gu (2010) also pointed out the weakest point for those who are identity foreclosure and described that these persons have not experienced an identity crisis. They tend to conform to the expectations of others regarding their future (e.g., allowing a parent to determine a career direction). As such, these individuals have not explored a range of options. Therefore, it is concluded that these subjects cannot do their work properly. The findings of the present study appear to be supported by the majority of earlier studies. Hejazi (2009), in which most of the researches have indicated that identity achievement has positive effect on academic achievement and identity foreclosure has negative effect on academic achievement.

Among these four subscales of ego identity, identity-achievement indicates the highest relationship and identity-foreclosure shows the lowest relationship with academic achievement. The present findings indicated that foreclosed academic identity and diffusion academic identity are related to academic achievement negatively and achievement academic identity is connected to academic achievement positively. As diffusion has highest negative relationship with academic achievement, so the level being successful in academic course will highly be decreased, as Adams (1989), denoted diffusion as an indifference and lack of interest regarding identity issues and individuals with this quality are unmotivated with inadequate identity awareness who had withdrawn from exploration. In explaining this result, it should be noted that people with foreclosed academic identity are not self-regulated but are other-regulated. And also make use of learning strategies offered by other important people. It seems that this academic identity status is not an adaptive strategy for achieving in university. Wright (2011), 
Ego identity, self-esteem, and academic achievement among EFL learners: A relationship study

denoted individuals in the moratorium, critically assessed alternatives related to significant life choices.

Based on the obtained results, students with identity achievement have the highest degrees of self-esteem, it means that the learners who have effective decision making and unbiased thinking have high degrees of self-esteem. And after that students with identity moratorium, in other words, learners who examined life choices have lower degrees of self-esteem with respect to students with identity achievement, besides students with identity foreclosure have the lowest degrees of self-esteem. Furthermore, as identity diffusion of the students which has negative effect on self-esteem of the students are increasing and these persons have unmotivated characteristic toward learning, the self-esteem of these students are being decreased. Moreover, when identity achievement and identity moratorium of the students are augmenting, the levels of their self-esteem are increasing. Diffuse academic identity status predicts the highest negative relationship with academic achievement. According to Was (2009), diffuse academic identity is marked by the failure in exploration and commitment to academic values. The present findings indicated that foreclosed academic identity is related to academic achievement negatively. In explaining this result, it should be noted that people with foreclosed academic identity make use of learning strategies. It seems that this academic identity status is not an adaptive strategy for achieving in university. In considering to results, identity achievement has the highest and positive relationship with academic achievement.

\section{References}

Adams, G. R. (1989). Objective measure of ego identity status: A reference manual. Unpublished manuscript available at the University of Guelph, Ontario, Canada.

Agolla, J. E. (2009). The relations between ego identity and self-esteem among undergraduate students: The Case of University of Botswana. Educational Research and Review, 4(2), 63-70.

Bennion, L. D., \& Adams, G. R. (1986). A revision of the extended version of the objective measure of Ego Identity Status: An identity instrument for use with late adolescents. Journal of Adolescent Research, 1(2), 183-198. https://doi.org/10.1177/074355488612005

Branden, N. (1991). The psychology of self-esteem. New York: Bantam.

Coopersmith, S. A. (1981). The antecedents of self-esteem. New York: Batman.

Erikson, E. H. (1980). Identity and the life style. New York: W.W. Norton.

Freud, A. (1970). The ego and mechanisms of defense. Oxford, UK: International Universities Press.

Gu, M. M. (2010). Ego identities constructed in difference: English language learners in China. Journal of Pragmatics, 42(1), 139-152. https://doi.org/10.1016/j.pragma.2009.06.006

Hartmann, H. (1980). Papers on psychoanalytic psychology. Psychological Issues. Monograph No. 14. New

York: International Universities Press.

Hejazi, E. (2009). Identity style and academic achievement: mediating role of academic self-efficacy. Social Psychology of Education, 12, 123-135. https://doi.org/10.1007/s11218-008-9067-x

Josselson, R. (1982). Personality structure and identity status as viewed through early memories. Journal of Youth and Adolescence, 11(1), 293-299. https://doi.org/10.1007/BF01537171

Kroger, J. (2000). Identity status and locus of control: A meta-analysis. An International Journal of Theory and Research, 3(13), 253-265.

Lane, J. (2004). Self-efficacy, self-esteem and their impact on academic performance. Social Behavior and Personality, 32(3), 247-256. https://doi.org/10.2224/sbp.2004.32.3.247

Marcia, J. E. (1980). Identity in adolescence In J. Andelson (Eds.), Handbook of Adolescent Psychology, 21(1), 149-160.

Moshman, D. (2005). Adolescent psychological and ideological development: Rationality, morality, and identity ( $2^{\text {nd }}$ ed.). Mahwah, NJ: Lawrence Erlbaum Associates.

Pajares, F. (2003). Self-esteem beliefs, motivation, and achievement in writing: A review of the literature. Reading and Writing Quarterly, 19(4), 139-158. https://doi.org/10.1080/10573560308222

Rosenberg, M. (1965). The nature of self-esteem. Journal of Human Psychology, 11(1), 45-60. 
Mohammadi, H., \& Akbari, O.

Rosenberg, M. (1986). Conceiving the self. New York: Basic Books.

Was, C. A. (2009). The relationship between ego identity and academic achievement. Electronic Journal of Research in Educational Psychology, 7(2), 627-652.

Wright, B. L. (2011). I know who I am, do you? Identity and academic achievement of successful African American male adolescents in an urban pilot high school in the United States. Urban Education, 46(4), 611-638. https://doi.org/10.1177/0042085911400319 